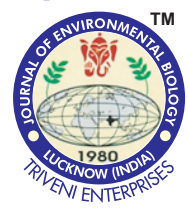

\title{
Physico-chemical characteristics and thermal stability of calcium oxalate crystals isolated from Beta vulgaris root
}

\begin{abstract}
Authors Info
S. Subashini and

K. Sathishkumar*

Department of Chemical Engineering, Sri Sivasubramaniya Nadar College of Engineering, Kalavakkam - 603 110, India

*Corresponding Author Email : sathishkumark@ssn.edu.in

\section{Edited by}

Professor M. Seenuvasan

Reviewed by Professor G. Manjula Professor N. K. Dubey

\section{Abstract}

Aim: Beta vulgaris is an edible plant whose roots and leaves are consumed. Beta vulgaris contain both water soluble and insoluble oxalates. In the present study calcium oxalate crystals were isolated from Beta vulgaris root.

Methodology: Physico-chemical characteristics and thermal stability of isolated crystals were analyzed using various spectroscopic and microscopic methods such as SEM, TEM, FT-IR, NMR, TGA and DSC.

Results: The crystalline structure was confirmed by X-Ray Diffraction analysis with a $2 \theta$ value of $20^{\circ}$. Functional groups observed in FTIR and $1 \mathrm{H}-\mathrm{NMR}$ spectrum confirmed the presence of calcium oxalate in Beta vulgaris root isolate. The presence of calcium with sharp peaks at 0.3 and $3.68 \mathrm{keV}$ was confirmed using EDS analysis. The size of calcium oxalate crystals in Beta vulgaris root isolate was found within 100 $\mathrm{nm}$ by TEM with SAED. Thermal stability of calcium oxalate crystals was found in the range of 150 to $200^{\circ} \mathrm{C}$ using TGAand DSC.

Interpretation: Calcium oxalate crystals in Beta vulgaris are water insoluble and thermally stable.

Key words: Beta vulgaris, Biogenic crystals, Calcium oxalate, Thermal stability

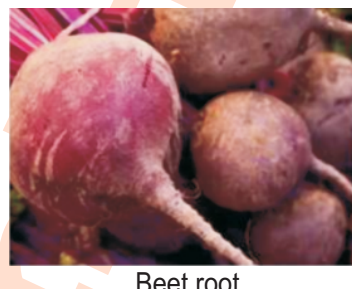

Beet root

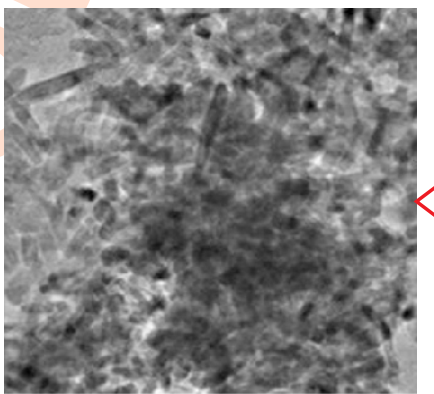

TEM image of calcium oxalate crystals
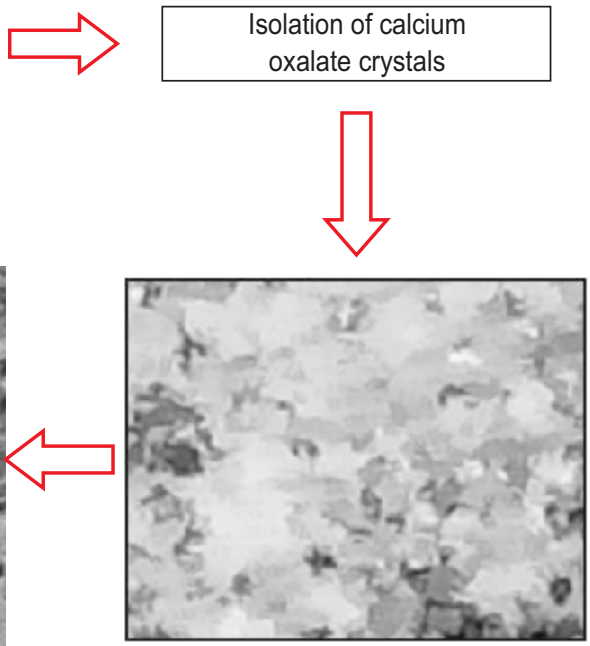

Isolated calcium oxalate crystals

How to cite : Subashini, S. and K. Sathishkumar: Physico-chemical characteristics and thermal stability of calcium oxalate crystals isolated from Beta vulgaris root. J. Environ. Biol., 40, 775-783 (2019). DOI: http://doi.org/10.22438/jeb/40/4(SI)/JEB_19
\end{abstract}




\section{Introduction}

Beta vulgaris (beet root) is commonly used edible plant. It has antitumor, antioxidant, carminative and hemostatic properties and contain calcium, phosphorous, iron, vitamins, niacin, thiamine and riboflavin (Fugh-Berman et al., 2004; Stintzing and Carle, 2004; Simpson et al., 2009). Beet root juice is used as natural colorant in food industry. There is a concern over the consumption of beet root during pregnancy and lactation for safety. Excess consumption of beet root is not advised due to accumulation of calcium, copper, iron, magnesium, manganese, phosphorus and zinc in the liver (Blázovics et al., 2007).

Crystals of calcium oxalate $\left(\mathrm{CaC}_{2} \mathrm{O}_{4}\right)$ are formed is plants by endogenously synthesized precursors and calcium from soil solution (Libert and Franceschi, 1987; White and Broadley, 2003; Nakata, 2005; Franceschi and Nakata, 2005; Parvathi and Subbulakshmi, 2016). Oxalic acid and L-ascorbic acid in plants are the major precursors to convert calcium present in plants to calcium oxalate. Crystals in plants serve as structural supports for their growth, calcium oxalate crystals occur in many plants and in most organs and tissues (Franceschi and Horner, 1980; Holloway et al., 1987; Oscarsson et al., 2007). Calcium oxalate in plants are highly crystalline and are not damaged during extraction (da Costa et al., 2009).

High calcium oxalate concentration in edible plants cause renal problems in human (Romero et al., 2010). Excess consumption of calcium oxalate leads to hyperoxaluria. Patients complaining of hyperoxaluria have been found to have calcium oxalate kidney stones (Williams and Wandzilak, 1989; Massey et al., 1993; McAlister John et al., 2000; ADA, 2005; Finkielstein and Goldfarb, 2006). Cattles fed with large amount of Beta vulgaris stems/leaves have been reported to show infertility and genital tract abnormalities whereas in mice, increase in uterine weight has been observed (Fugh-Berman et al., 2004; Sembries et al., 2006).

Patients from kidney deceases are suggested to avoid food that contain high amount of calcium oxalate. Spinach, cranberries, celery, peanuts, parsley, soya products, fibercontaining cereals, chocolates and bran contain high amount of calcium oxalate (McHarg et al., 2003; Radek and Savage, 2008; Savage and Martensson, 2010; WFBMC, 2015; Siener et al., 2016). On the other hand, addition of yoghurt in fried leaves of Beta vulgaris var. cicla has been found to reduce soluble calcium oxalate (Johansson and Savage, 2011). Similarly, use of enzyme oxalate oxidase also reduces oxalate in red beetroot, however, the process is expensive due to use of enzyme (Enkhtuya et al., 2012). In view of the above, the present study was carried out to assess the physico-chemical characteristics and thermal stability of calcium oxalate crystals isolated from Beta vulgaris root.

\section{Materials and Methods}

Preparation of Beta vulgaris root sample: Beta vulgaris was purchased from local market, Chennai, India. Leaves and stems were removed and the roots were washed thoroughly with double distilled water. Washed root was air dried for 30 min to remove excess water. The root was sliced into small pieces and refrigerated at $4^{\circ} \mathrm{C}$ overnight.

Isolation of calcium oxalate crystals from Beta vulgaris root: Refrigerated Beta vulgaris root sample $(50 \mathrm{~g})$ was mixed with 50 $\mathrm{ml}$ of double distilled water and homogenized in high speed mixer to produce juice. The juice was filtered through a $0.2 \mathrm{~mm}$ sieve to separate Beta vulgaris root tissues. The juice containing calcium oxalate crystals was collected. Root tissues retained in the sieve was ground again with equal volume (v:w) of double distilled water and the juice was collected by filtration. The procedure was repeated until the plant juice becomes clear (da Costa et al., 2009). Juice was centrifuged at $6000 \mathrm{rpm}$ for $30 \mathrm{~min}$ to separate calcium oxalate crystals with fine plant tissues. Supernatant was discarded and the pellet was dried at $65^{\circ} \mathrm{C}$ for overnight. Dried material was mixed with hydrogen peroxide $(30 \%)$ and allowed to settle overnight to digest and remove the organic impurities. Resultant sediment was washed with double distilled water and dried again at $65^{\circ} \mathrm{C}$ overnight. The dried isolate containing calcium oxalate was used for further characterization.

Physico-chemical characterization of calcium oxalate crystals in Beta vulgaris root: Physico-chemical characteristics of calcium oxalate crystals in aqueous extract of Beta vulgaris root were studied by the following methods. To study the morphology and elemental composition the sample was examined by Scanning Electron Microscope (SEM) (QUANTA 200) with magnification range 35 to 30,000 , equipped with Energy Dispersive Spectroscopy (EDS). The characteristic functional groups present in Beta vulgaris root isolate was analyzed by Fourier Transform Infra-Red (FTIR) spectroscopy (BRUKER a$\mathrm{T})$. The sample was mixed with binding agent $(\mathrm{KBr})$ and made into disc at high pressure using hydraulic press. The disc was scanned in the range of 400 to $4000 \mathrm{~cm}^{-1}$ to obtain FTIR spectrum. Inorganic compounds present in Beta vulgaris root isolate was studied using Proton Nuclear magnetic resonance spectroscopy ('H-NMR). Crystallinity of calcium oxalate crystals in Beta vulgaris root extract was studied using X-ray diffraction spectroscopy (XRD). Approximately, $1 \mathrm{~g}$ of dried sample was used for XRD analysis using XPERT-PRO diffractometer. Effect of temperature on calcium oxalate crystals isolated from Beta vulgaris root was studied using Thermogravimetric (TG) and Differential Scanning Calorimetric (DSC) analysis. The particle size distribution and diffraction of calcium oxalate crystals were analyzed by High Resolution-Transmission Electron Microscopy (HR-TEM) with Selective Area Electron Diffraction (SAED) (HR-TEM; JEOL2100 Plus).

\section{Results and Discussion}

Scanning electron microscopy was carried out to study the morphological and structural characteristics of crystalline 
materials in Beta vulgaris root isolate. The SEM images of Beta vulgaris root isolate at different resolution (Fig. 1) confirmed, the presence of crystalline substances in Beta vulgaris root isolate. The clarity of shape of crystalline materials increased with increase in the resolution from 6000 to $50000 x$ (Fig. 1). The spherical shaped crystals in Beta vulgaris root isolate was confirmed. Further, SEM images also revealed that the crystals present Beta vulgaris root isolate were spurious in nature.

Composition of various components present in Beta vulgaris root isolate was studied using EDS analysis. The presence of calcium with sharp peaks at 0.3 and $3.68 \mathrm{keV}$ and oxygen with a peak at $0.26 \mathrm{keV}$ was observed in EDS spectrum as shown in Fig. 2. The crystals present in Beta vulgaris root isolate were confirmed as calcium oxalate crystals. The major peak at $0.12 \mathrm{keV}$ represents the presence of excess carbon in Beta vulgaris root isolate.
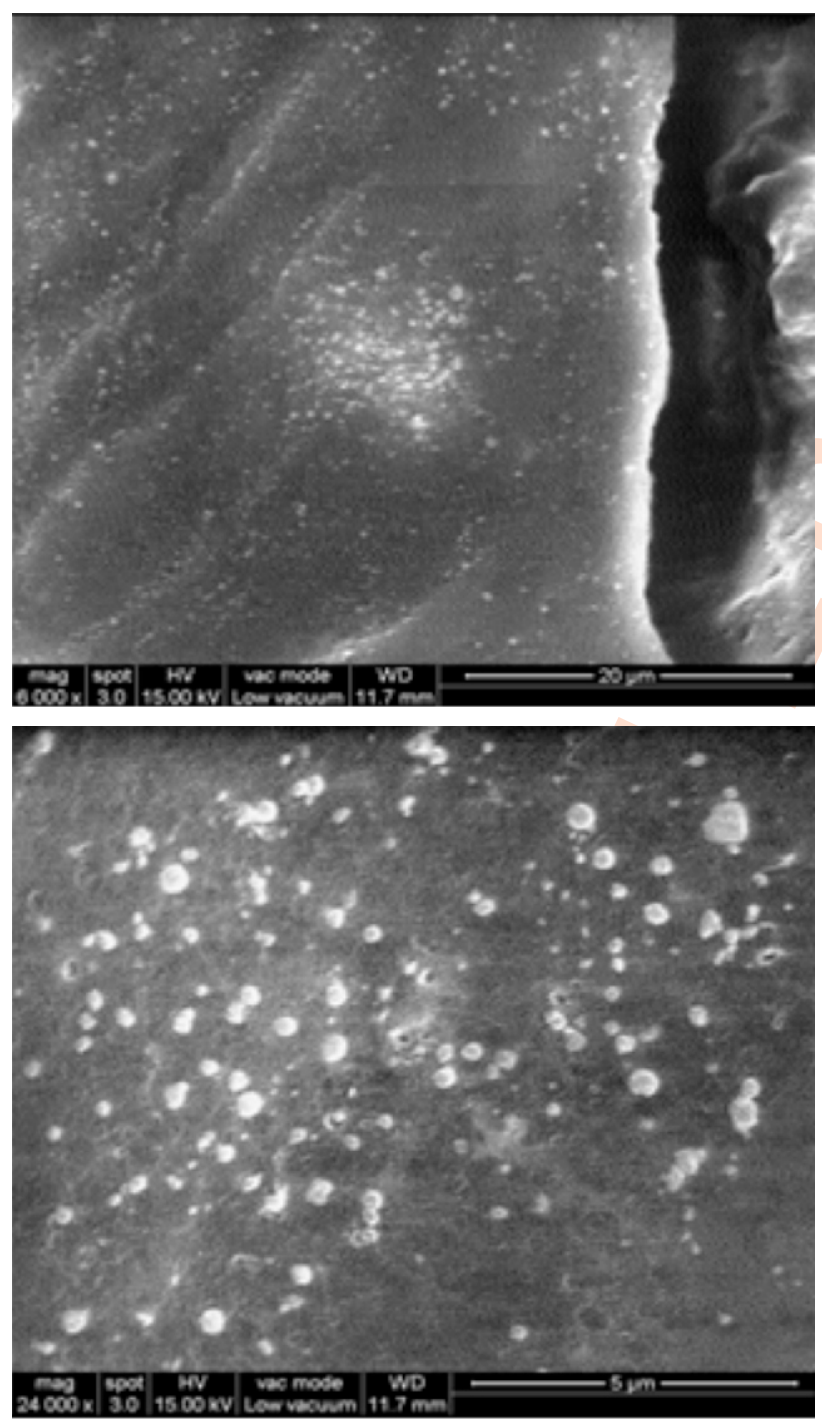

HR-TEM image of calcium oxalate crystals isolated from Beta vulgaris root is shown in Fig. 3. The micrographs showed uniform size and compact distribution of calcium oxalate crystals within $100 \mathrm{~nm}$. The presence of calcium oxalate rich crystals with low dense (low contrast) is shown in Fig. 3. The rod shaped particles at darker region were of the same order of magnitude to that of Dynamic Light Scattering (DLS). The size observed is in good agreement with the DLS on the onset of nucleation of calcium crystals. The SAED pattern of calcium oxalate crystals is shown in Fig. 4. The spots noted in SAED pattern confirmed the diffraction pattern of selected region. The spot at this region confirmed the presence of calcium oxalate in crystalline form. The bright spots with certain diffused rings were noted (Fig. 4). The smaller spots arised due to the Bragg reflection of an individual crystalline particle. The SAED pattern gives information about the growth orientation of thin film and cap layer. The tilt axis with respect to electron beam was observed. The electron beam was perpendicular to the plane and
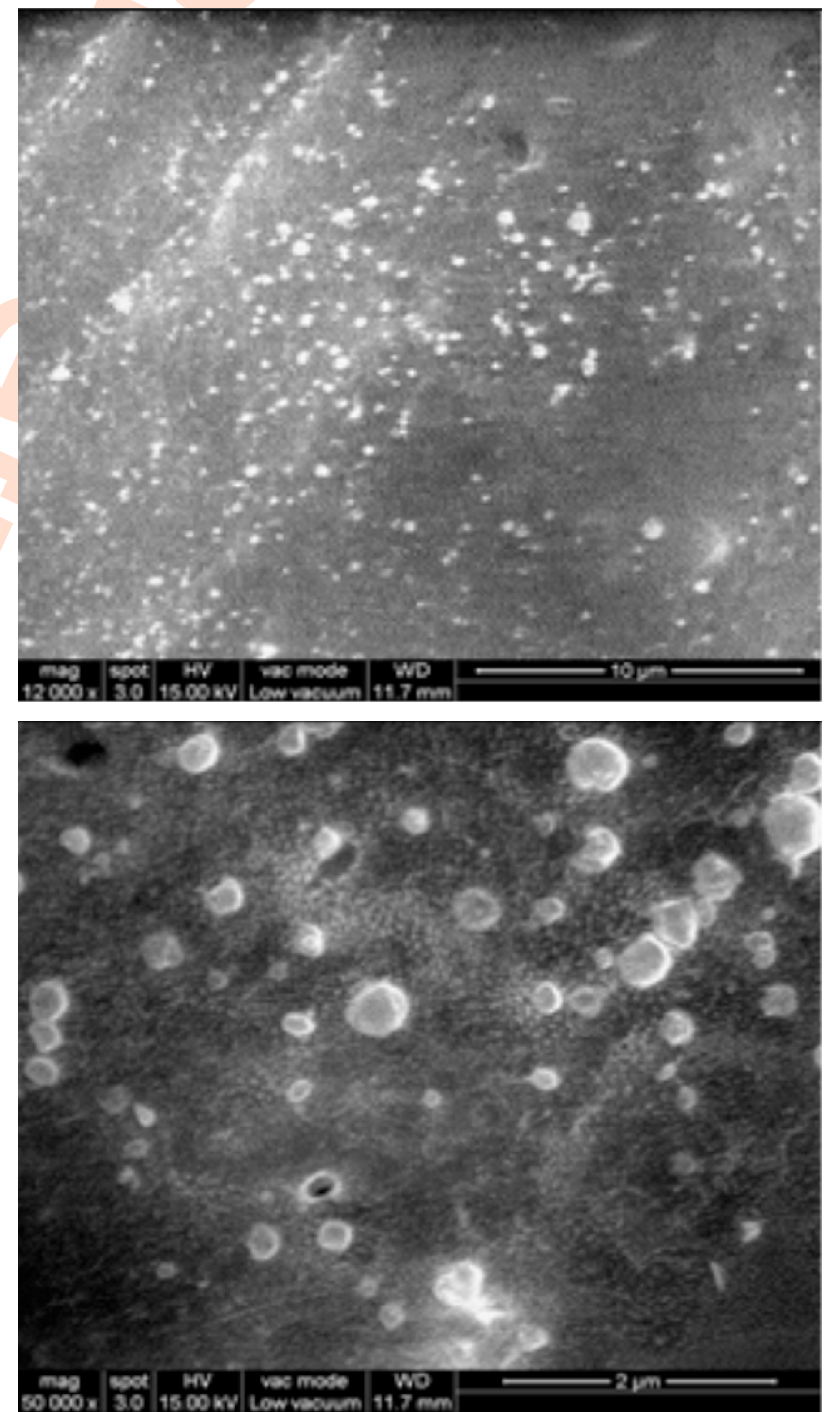

Fig. 1 : Surface characteristics of Beta vulgaris root isolate using Scanning Electron Microscope. 


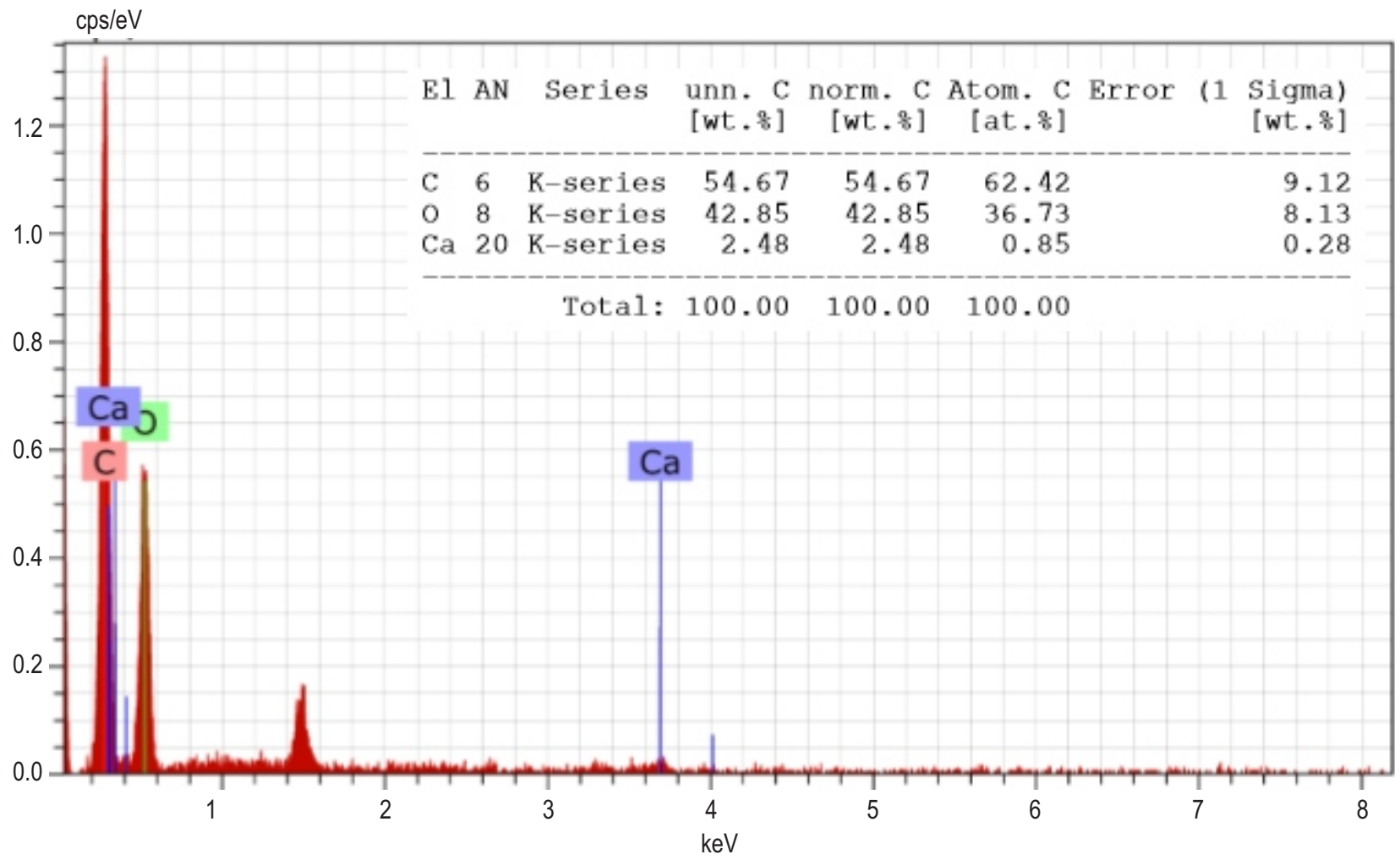

Fig. 2 : Elemental analysis of Beta vulgaris root isolates using Energy Dispersive Spectroscopy.
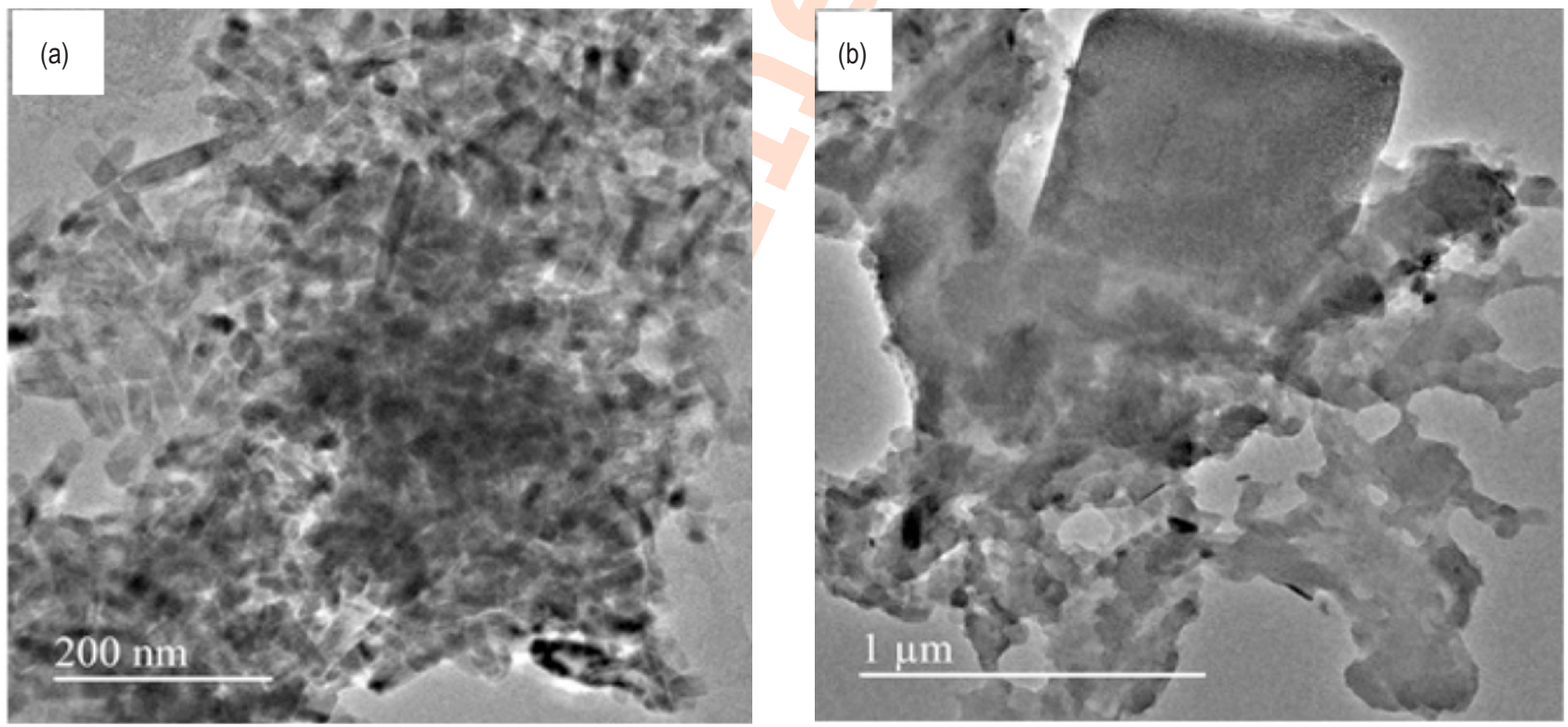

Fig. 3 : High resolution transmission electron microscopy analysis of calcium oxalate isolated Beta vulgaris root.

the change in the tilt angle was also observed at the outer region. The change in the tilt axis decreased the projection of the sample with diffused arrangement of lattice patterns. The SAED pattern also confirmed the broadening of diffraction and fractional peak with respect to the change in the scattering angle.
The Crystalline nature of calcium oxalate from Beta vulgaris root isolate was studied using $X$-ray diffraction analysis. The XRD pattern was recorded for $2 \theta$ of brag angle ranging from $10-100^{\circ}$ as shown in Fig. 5. The sharp peak at $15^{\circ}$ and $20^{\circ}$ confirmed that the crystal present in Beta vulgaris root isolate was 


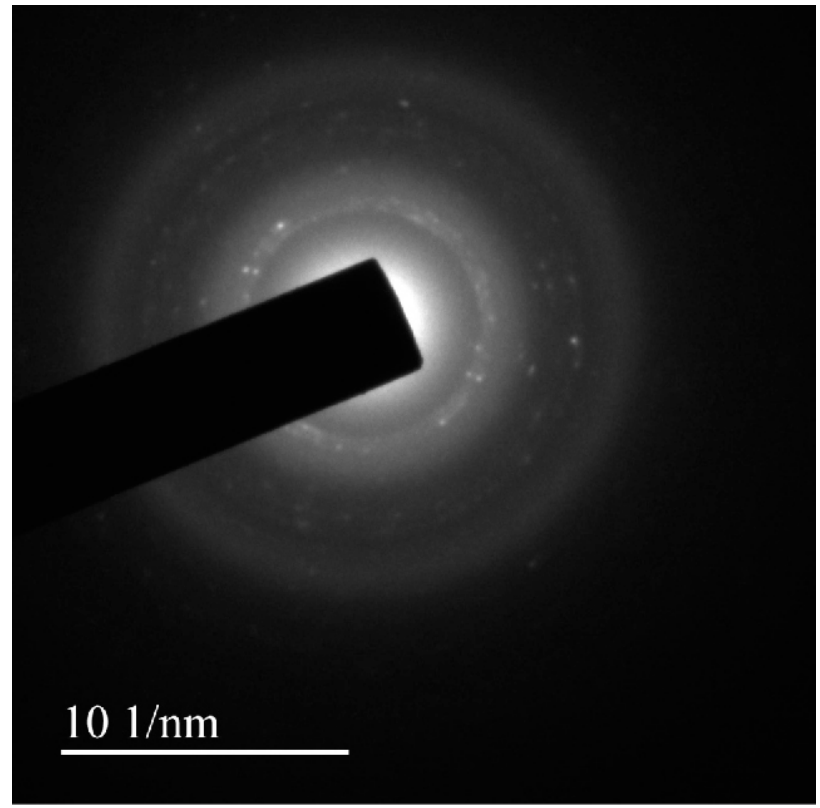

Fig. 4 : SAED pattern of calcium oxalate from Beta vulgaris root.

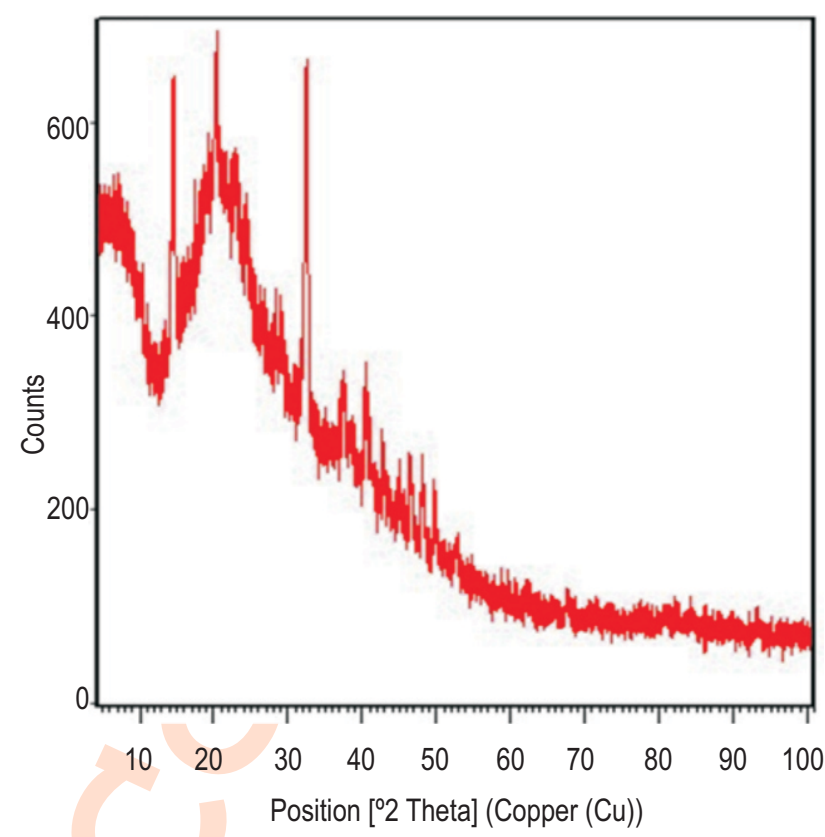

Fig. 5 : XRD Spectrum of calcium oxalate from Beta vulgaris root.

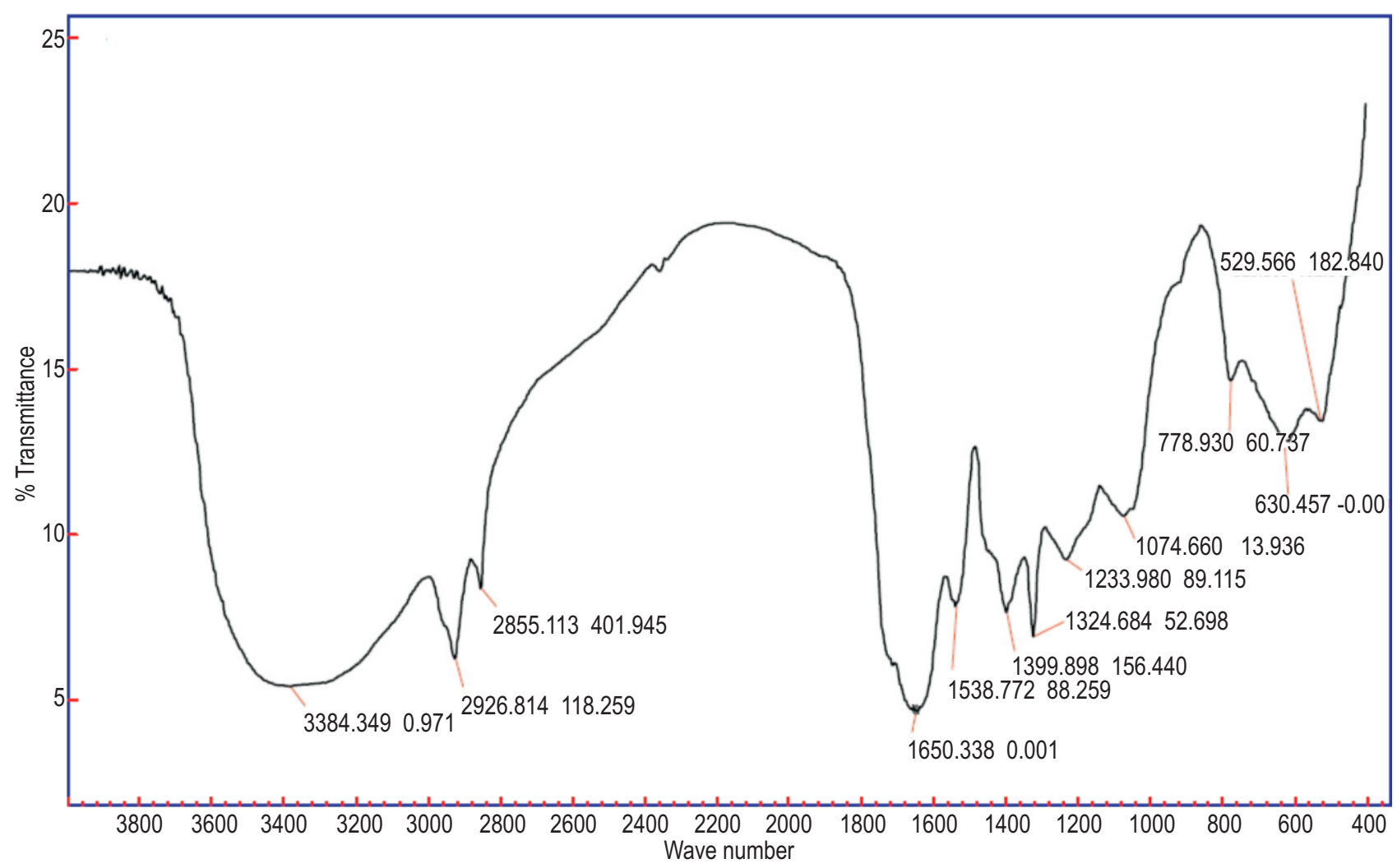

Fig. 6 : Fourier Transform Infra Red spectroscopy spectrum of calcium oxalate from Beta vulgaris root.

calcium oxalate. The diffraction peak obtained at 15, 20, 32, 36 and $40^{\circ}$ confirmed the crystalline structure with respect to corresponding lattice parameters (McAlister John et al., 2000; Manjula et al., 2012).
The FTIR spectrum exhibit typical inorganic features dependent on atomic masses, interatomic forces and molecular geometry. All complex ionic compounds and coordination compounds produce characteristic FTIR spectrum. Inorganic 
compounds that form bonds of covalent nature within a molecular ion fragment produce a characteristic absorption FTIR spectrum, with associated group frequencies (John, 1999). Inorganic compounds with oxygenated functional group, compounds present in the form of salts of carboxylic acids, and amino and ammonium can be identified using FTIR (NICODOM, 2006; Manjula et al., 2012). The FTIR spectrum of Beta vulgaris root isolate shown in Fig. 6, confirmed the presence of inorganic functional groups. The distinct and broad vibration between 3000 to $3600 \mathrm{~cm}^{-1}$ and a peak, particularly at $3384.35 \mathrm{~cm}^{-1}$ correspond to broad calcium oxalate monohydrate strong band. Peaks at $1399.89,1233.98$ and $1074.66 \mathrm{~cm}^{-1}$ confirmed the presence of C$O$ group stretch vibration. Peaks at 778.93, 781, 630.45, 665 and 529.56 and $520 \mathrm{~cm}^{-1}$ indicated the presence of strong calcium hydroxide monohydrate bands whereas peaks at 1650.38 , $1324.68,778.93,630.45$ and $529.56 \mathrm{~cm}^{-1}$ also indicated the presence of strong calcium hydroxide monohydrate bands (McAlister John et al., 2000; John 1999). Thus, the presence of calcium oxalate crystals in Beta vulgaris root isolate was confirmed by FTIR analysis.
The analysis of ${ }^{1} \mathrm{H}$-NMR spectrum (Fig. 7) of Beta vulgaris root isolate confirmed the presence various functional groups (Table 1). A short narrow single peak ranging between 0.5-0.9 ppm, particularly at $0.852 \mathrm{ppm}$ in Beta vulgaris root isolate showed the presence of methyl alkyl and alcohol groups. A sharp narrow single peak ranging between 1.0-1.3 ppm (1.241 ppm) in Beta vulgaris root isolate indicated the presence of secondary alkyl groups. Short narrow singlet peak between 1.4-1.6 ppm in root corresponds to the presence of tertiary alkyl groups. Weak minor peaks ranging between 1.7-2.0 ppm indicated the presence of allylic carbon. Double peak ranging between 2.1-2.4 ppm in root represented the presence of methyl ketone and ester functional groups. Thus, ${ }^{1} \mathrm{H}-\mathrm{NMR}$ spectrum analysis confirmed that inorganic functional group constitutes Beta vulgaris root isolate (Subashini and Sathishkumar, 2017).

Shape of TGA curve show the characteristic effect of heating rate applied, and this also gives the information about the escape of moisture with respect to melting temperature. The decomposition plot of calcium oxalate crystals isolated from Beta
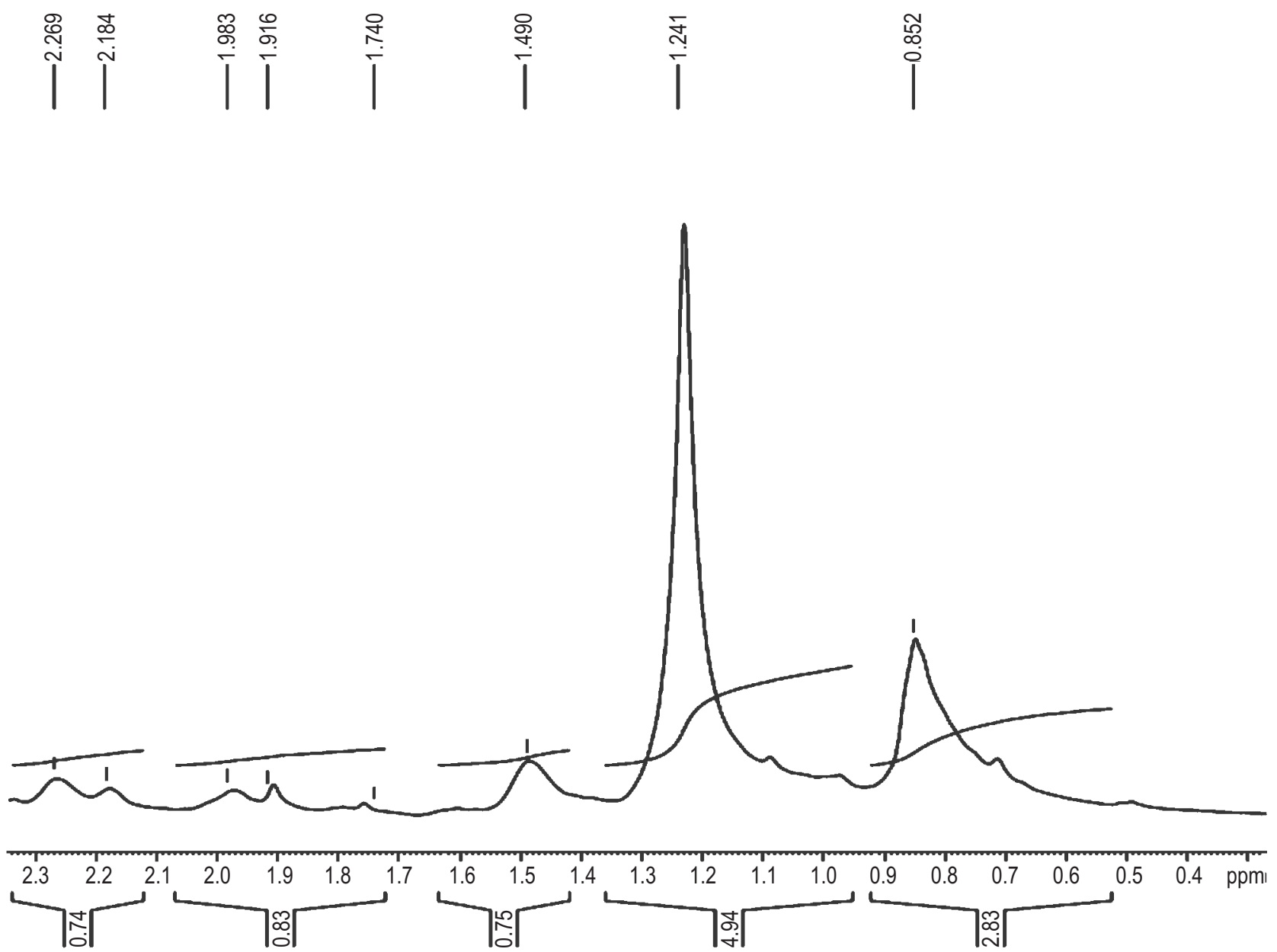

Fig. 7 : 1H-NMR spectrum of calcium oxalate from Beta vulgaris root. 
TG / \%

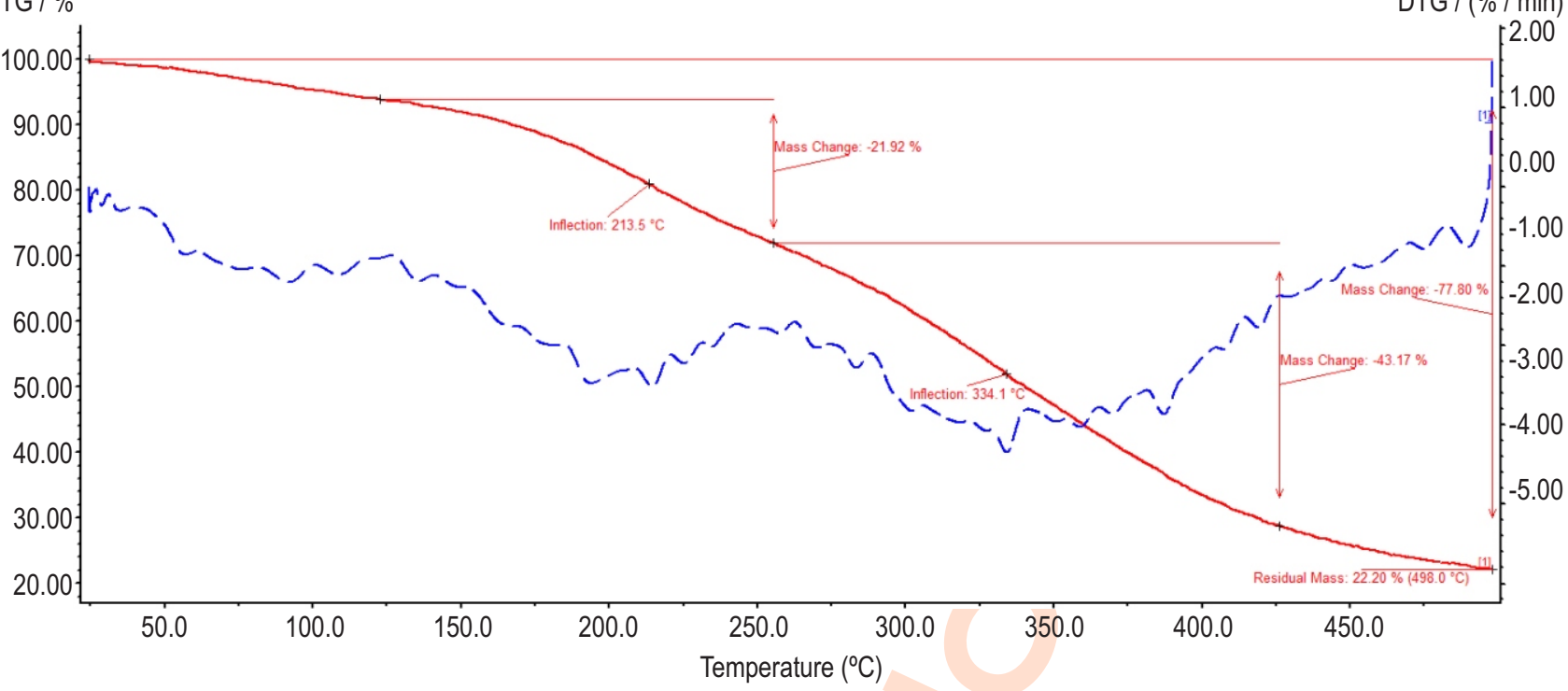

Fig. 8 : TG and DTG analysis of calcium oxalate from Beta vulgaris root.

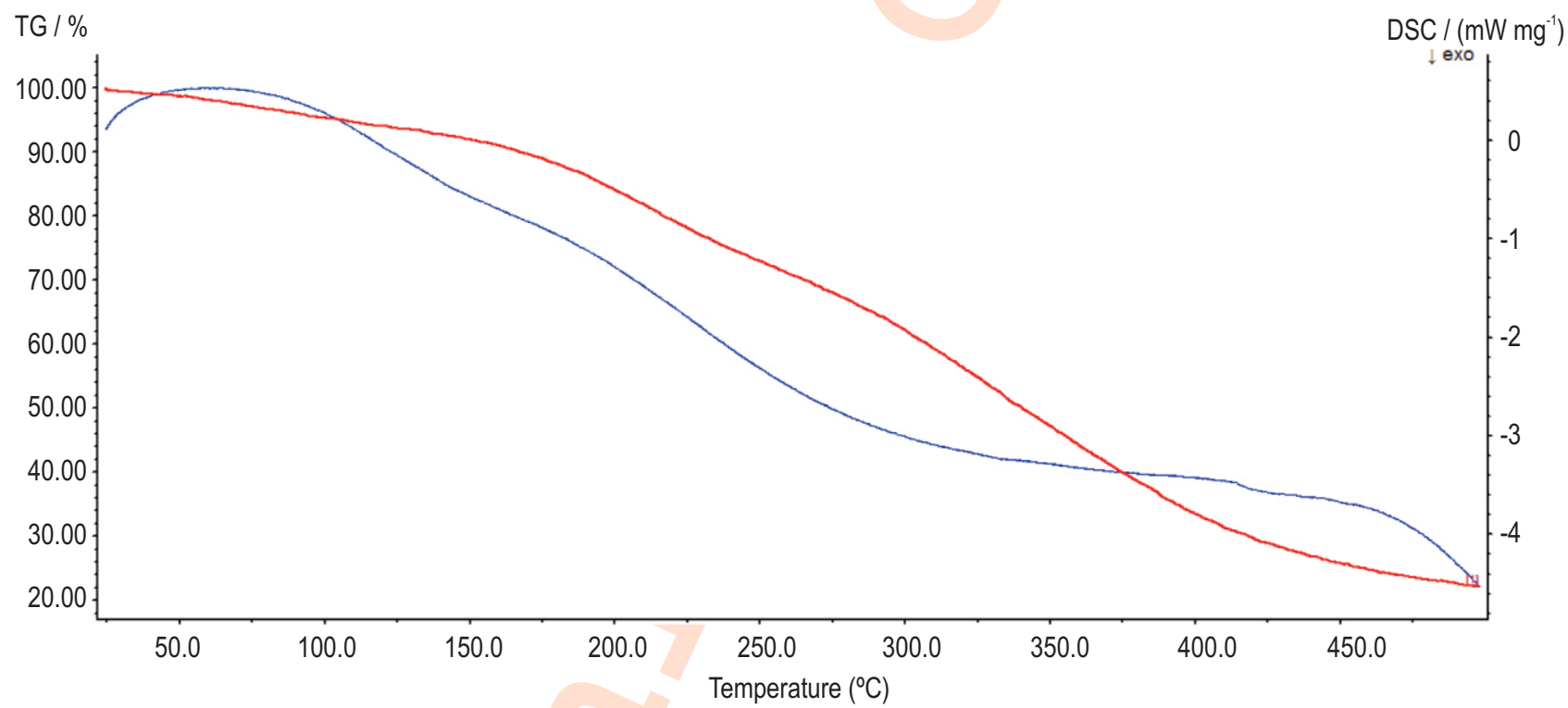

Fig. 9 : TG and DSC analysis of calcium oxalate from Beta vulgaris root.

vulgaris root with respect to temperature and mass fraction is shown in Fig. 8. The TG curve confirmed the single stage decomposition of calcium oxalate crystals in a nitrogen atmosphere at a heating rate of $10 \mathrm{~K} \mathrm{~min}^{-1}$. The TG curve shows mass loss step with residual mass by $22.20 \%$ at $498.0^{\circ} \mathrm{C}$. Fig. 8 shows high thermal stability until its inflection point at $334.1^{\circ} \mathrm{C}$. The weight loss profile obtained at $125,250,425^{\circ} \mathrm{C}$ shows the change in the residual mass after its exposure to higher temperature. The TG-DTG curve (Fig. 8) shows the weight loss of compound obtained due to loss of water present in crystals and physical transitions occurs during onset and end set temperatures. The other thermal method of analysis is DSC. DSC is used to study the change in phase formation with temperature and enthalpy. The degree of crystallization was determined based on the molecular structure of the sample. The plot of TG-DSC for calcium oxalate crystals isolated from Beta vulgaris root (Fig. 9) showed that increase in temperature initiates the loss of water molecule in the range of $150-200^{\circ} \mathrm{C}$. Thermal stability of compound was noted to be higher in the range of 150 to $200^{\circ} \mathrm{C}$. The melting enthalpy confirmed the crystalline nature of compounds in the range of $150-200^{\circ} \mathrm{C}$ confirming the endothermic nature of crystalline materials. 
Table 1: Chemical shoft of functional groups in Beta vulgaris root isolate by ${ }^{1} \mathrm{H}-\mathrm{NMR}$ analysis

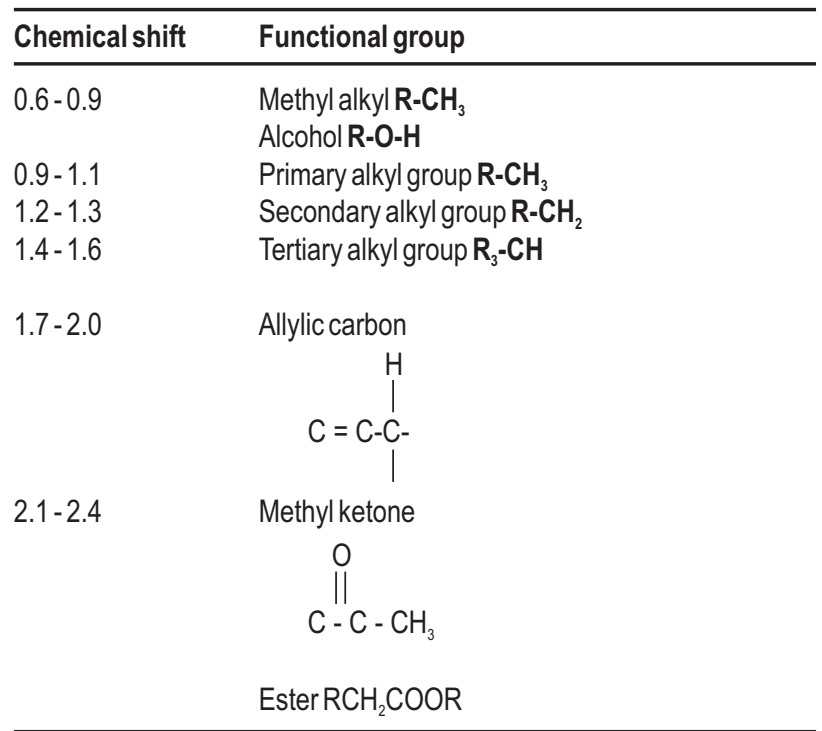

The presence of calcium oxalate crystals in Beta vulgaris root isolate was confirmed with peak at $3384.35 \mathrm{~cm}^{-1}$ in FTIR spectrum. The crystalline structure of calcium oxalate crystals in Beta vulgaris root was confirmed by X-Ray Diffraction analysis with a $2 \theta$ value of $20^{\circ}$. The spherical shape and spurious nature of calcium oxalate crystals in Beta vulgaris root was confirmed by SEM analysis. Beta vulgaris root is reported for significant portion of calcium oxalate crystals as confirmed by ${ }^{1} \mathrm{H}-\mathrm{NMR}$ and EDS analysis. Thus the human with renal problems or kidney stones are suggested to avoid the consumption of Beta vulgaris root.

\section{References}

ADA (American Dietetics Association): Urolithiasis/urinary stones. In ADA Nutrition Care, Manual No. 275. Chicago: American Dietetics Association (2005).

Blázovics, A., E. Sárdi, K. Szentmihályi, L. Váli, M. Takács-Hájos and E. Stefanovits-Bányai: Extreme consumption of Beta vulgaris var. rubra can cause metal ion accumulation in the liver. Acta Biol. Hung., 58, 281-286 (2007).

da Costa, L.M., J. Tronto, V.R.L. Constantino, M.K.A. Fonseca, A.P. Oliveira and M.R. da Costa: Extraction and concentration of biogenic calcium oxalate from plant leaves. Rev. Bras. Ciênc. Solo., 33, 729-733 (2009).

Enkhtuya, N., D. Baatar and L. Odontuya: Possible ways of decreasing oxalate content in red beet foods. Proc. Mong. Acad. Sci., 52, 5556 (2012).

Finkielstein, V. and D. Goldfarb: Strategies for preventing calcium oxalate stones. Can. Med. Assoc. J., 174, 1407-1409 (2006).

Franceschi, V.R. and H.T. Horner: Calcium oxalate crystals in plants. Bot. Rev., 46, 361-427 (1980).

Franceschi, V.R. and P.A. Nakata: Calcium oxalate in plants: Formation and function. Ann. Rev. Plant Biol., 56, 41-71 (2005).

Fugh-Berman, A., M.J. Balick, F. Kronenberg, A.L. Ososki, B. O'Connor,
M. Reiff, M. Roble, P. Lohr, B.J. Brosi and R. Lee: Treatment of fibroids: the use of beets (Beta vulgaris) and molasses (Saccharum officinarum) as an herbal therapy by Dominican healers in New York City. J. Ethnopharmacol., 92, 337-339 (2004).

Guil-Guerrero, J.L.: The safety of wild edible plants: Fuller discussion may be needed. J. Food Compos. Anal., 35, 18-20 (2014).

Holloway, W.D., M.E. Argall, W.T. Jealous, J.A. Lee and J.H. Bradbury: Organic acids and calcium oxalate in tropical root crops. J. Agric. Food Chem., 37, 337-341 (1989).

Johansson, S. and G. P. Savage: The availability of soluble oxalates in stir-fried silver beet (Beta vulgaris var. cicla) leaves eaten with yoghurt. Int. J. Food Sci. Technol., 46, 2232-2239 (2011).

John, C.: Interpretation of Infrared Spectra: A Practical Approach. Encyclopedia of Analytical Chemistry, (Ed.: R.A. Meyers), John Wiley \& Sons Ltd., Chichester. UK. (1999).

Libert, B. and V.R. Franceschi: Oxalate in crop plants. J. Agric. Food Chem., 35, 926-938 (1987).

Manjul, K., K. Pazhanichamy, S. Kumaran, T. Eevera, C.D. Keefe and K. Rajendran: Growth characterization of calcium oxalate monohydrate crystals influenced by Costus igneus aqueous stem extract. Inter. J. Phar. Pharma. Sci., 4, 261-270 (2012).

Massey, L.K., H.R. Smith and R.A.L. Sutton: Effect of dietary oxalate and risk of formation of calcium oxalate kidney stones. J. Am. Diet. Assoc., 93, 901-906 (1993).

McAlister John, J., J.S. Bernard and A.B.N. Jose: The presence of calcium oxalate dihydrate (Weddellite) in street sediments from Niterói, Brazil and its health implications. Environ. Geochem. HIth., 22, 195-210 (2000)

McHarg, T., A. Rodgers and K. Charlton: Influence of cranberry juice on the urinary risk factors for calcium oxalate kidney stone formation. BJU Int., 92, 765-768 (2003).

Nakata, P.A.: Advances in our understanding of calcium oxalate crystal formation and function in plants. Plant Sci., 164, 901-909 (2003).

NICODOM IR Inorganics. 1803 IR spectra of inorganics, Minerals (NICODOM Ltd.,) Czech Republic, EU (2006).

Oscarsson, K.V. and G.P. Savage: Composition and availability of soluble and insoluble oxalates in raw and cooked taro (Colocasia esculenta var. Schott) leaves. Food Chem., 101, 559-562 (2007).

Parvathi, and B. Subbulakshmi: Development of value added products from tropical tubers. J. Crop Weed, 12, 69-75 (2016).

Radek, M. and G.P. Savage: Oxalates in some Indian green leafy vegetables. Int. J. Food Sci. Nutr., 59, 246-260 (2008).

Rakesh, M., C. Bradley, L. Stephanie, A.T. Swathi and Q. Gloria: Extraction and estimation of the quantity of calcium oxalate crystals in the foliage of conifer and hardwood trees. Tree Physiol., 35, 574-580 (2015).

Romero, V., H. Akpinar and D.G. Assimos: Kidney stones: A global picture of prevalence, incidence and associated risk factors. Rev. Urol., 12, 86 (2010).

Savage, G.P. and L. Martensson: Comparison of the estimates of the oxalate content of taro leaves and corms and a selection of Indian vegetables following hot water, hot acid and in vitro extraction methods. J. Food Compos. Anal., 23, 113-117 (2010).

Sembries, S., G. Dongowski, K. Mehrländer, F. Will and H. Dietrich: Physiological effects of extraction juices from apple, grape, and red beet pomaces in rats. J. Agric. Food Chem., 54, 10269-10280 (2006).

Siener, R, A. Seidler, S. Voss and A. Hesse: The oxalate content of fruit and vegetable juices, nectars and drinks. J. Food Compos. Anal., $45,108-112(2016)$. 
Simpson, T.S., G.P. Savage, R. Sherlock and L. Vanhanen: Oxalate content of silver beet leaves at different stages of maturation and the effect of cooking with different milk sources. J. Agric. Food Sci., 57, 10804-10808 (2009).

Singh, A.K., A.K. Chaurasiya and S. Mitra: Oxalate content in elephant foot yam (Amorphophallus paeoniifolius Dennst-Nicolson) dry and fry cubes. J. Pharmac. Phytochem. 7, 2905-2909 (2018).

Stamatelou, K.K., M.E. Francis, C.A. Jones, L.M. Nyberg and G.C. Curhan: Time trends in reported prevalence of kidney stones in the United States: 1976-1994. Kidney Int., 63, 1817-1823 (2003).

Stintzing, F.C. and G. Carle: Functional properties of anthocyanins and betalains in plants, food, and in human nutrition. Trends Food Sci. Technol., 15, 19-38 (2004).

Subashini, S. and K. Sathishkumar: Physicochemical characteristics of calcium oxalate crystals in Spinacia oleracea. Indian J. Biochem. Biophy., 54, 156-163 (2017).

WFBMC (Wake Forest Baptist Medical Center). Medical Center Boulevard Winston-Salem, NC 27157, (2015).

White, P.J. and M.R. Broadley: Calcium in plants. Ann. Bot., 92, 487-511 (2003).

Williams, H.E. and T.R. Wandzilak: Oxalate synthesis, transport and the hyperoxaluric syndromes. J. Urol., 141, 742-749 (1989). 